\title{
A INFÂNCIA NO FILME O CONTADOR DE HISTÓRIAS: UMA ABORDAGEM SOCIOLÓGICA
}

\author{
Sônia Maria Fernandes dos Santos ${ }^{1}$ \\ lattes.cnpq.br/4807191261896297
}

\begin{abstract}
Resumo: Este artigo pretende suscitar reflexão a respeito das diferentes formas em que a criança é percebida nas produções cinematográficas, particularmente na película $O$ contador de histórias (2009), na tentativa de contribuir para o repertório de investigações sobre infância, bem como tentar compreender padrões sociais e de comportamentos no que se refere à infância e sua história - uma vez que muitos aspectos da infância contemporânea descendem do passado. Os estudos sobre infância alcançaram uma dimensão significativa e, com isso, têm proporcionado contribuições expressivas sob diversos enfoques, neste sentido, faz-se necessário estudar a infância, em perspectivas variadas, para tentarmos perceber os diferentes fenômenos sociais que dizem respeito à construção do sujeito criança. A escolha em repousar nossas análises em um filme é por acreditar que pelos filmes há a possibilidade da construção de representações sociais, bem como um forte potencial para influenciar comportamentos, isto é, os filmes têm a qualidade de registrar o passado e o contexto social e também de criar reminiscências históricas próprias. $\mathrm{O}$ aporte teórico para este estudo está baseado na Sociologia da Infância, uma vez que este campo "...insere-se decisivamente na construção da reflexividade contemporânea sobre a realidade social”, e devido ao fato que "as crianças constituem uma porta de entrada fundamental para a compreensão dessa realidade" (SARMENTO, 2009, p. 19).
\end{abstract}

Palavras-chave: Infância; Cinema; Sociologia da Infância.

\section{THE CHILDHOOD IN THE FILM O CONTADOR DE HISTÓRIAS: A SOCIOLOGICAL APPROACH}

\begin{abstract}
This article aims to encourage reflexion about the differents ways in which children is noticed in cinematographic productions, especially in the film $O$ contador de histórias (Luiz Villaça, Brazil, 2009), in an attempt to contribute to the research's repertoire of childhood, as well as try to understand social and behaviour standarts regarding childhoos and it's history - once that many childhood contemporary's aspects descendants of the past. The studies about childhood reached a significative dimension and, with that, have provided significant contributions under various focuses, in this sense, it's necessary to study childhood, in different perspectives, to try
\end{abstract}

${ }^{1}$ Doutoranda em Educação pela Universidade Federal do Pará (Brasil). Contato: soninhamar@uol.com.br. 
to understand the different social phenomena that relate to the construction of the subject child. The choice to rest our analysis in a movie is to believe that the films are the possibility of social representation's constrution, as well as a strong potential to influence behaviour, that is, films have the quality to record the past and the social context, but also, to create own historical reminiscences. The theoretical basis for this study is based on the Sociology of Childhood, since this field "...inserts decisively in the construction of modern reflexivity of social reality" and, due to the fact that "children form a fundamental gateaway to the understanding of this reality" (SARMENTO, 2009, p. 19).

Keywords: Childhood; Cinema; Childhood's Sociology.

\section{Introdução}

O texto fílmico é produto de configurações construídas, em linguagem cinematográfica, pela articulação de diferentes elementos: imagem em movimento, som musical, ruídos (sonoplastia), sons da fala e escrita. Isso faz do filme o resultado de um conjunto de significações que podem ser interpretadas e compreendidas de diversas maneiras. (DUARTE, 2009, p. 86).

É no século XVIII que surge uma emergente preocupação com a criança. Dessa forma, inicia-se um processo de cuidados específicos para com esse sujeito, portanto, protegê-lo e preservá-lo tonava-se essencial. Criança, agora, passa a ser vista não mais como uma reprodução do ser adulto, mas como alguém capaz de viver o seu mundo, sua infância. No entanto, a criança ainda pode ser considerada como sinônimo de dependência do adulto, embora devesse se abster das frustrações desse adulto; assim lhe seria permitido viver intensamente essa fase da vida.

Contraditoriamente, embora sempre tenham existido crianças - estes seres humanos jovens - desde o início de nossa existência, a infância - esta categoria social - nem sempre existiu, uma vez que a consciência social da infância começou a manifestar-se com o Renascimento (Séc. XVI-XVII), tornando-se independente a partir do Iluminismo (Séc. XVIII). 
Podemos considerar este fator um dos motivos para suscitar o interesse em estudos sobre infância, os quais alcançaram uma dimensão significativa. Além de terem proporcionado contribuições expressivas a fim de perceber os diferentes fenômenos sociais que dizem respeito à construção do sujeito criança, a partir de concepções que se mantêm presentes por toda a construção histórica da infância.

Segundo Corsaro (2011), determinados conceitos sobre a criança, na Sociologia, advêm "da ascensão de perspectivas teóricas interpretativas e construtivistas na sociologia”. Uma vez que nessas perspectivas, tudo o que está relacionado à origem e desenvolvimento dos seres humanos, até mesmo os conhecimentos científicos, são meticulosamente observados como construções sociais e não mais aceitos meramente como resultados da influência de fatores biológicos. O autor então afirma que,

Isso significa que a infância e todos os objetos sociais (incluindo os aspectos como classe, gênero, raça e etnia) são vistos como sendo interpretados, debatidos e definidos nos processos de ação social. Em suma, são vistos como produtos ou construções sociais. Quando aplicadas à sociologia da infância, as perspectivas interpretativas e construtivistas argumentam que as crianças, assim como os adultos, são participantes ativos na construção social da infância e na reprodução interpretativa de sua cultura compartilhada. Em contraste, as teorias tradicionais veem as crianças como "consumidoras" da cultura estabelecida por adultos. (CORSARO, 2011, p. 19)

Se assim compreendermos a infância como "produto ou construção cultural", e, as crianças como "participantes ativos na construção social da infância e na reprodução interpretativa de sua cultura compartilhada”, podemos inferir que as produções cinematográficas, ao [re]construir a infância na tela, estão embebidas de concepções e conceitos, sobre criança e infância, que se arrastam, teimosamente, em nossa sociedade ao longo da história.

Assim, o cinema "transformou-se em uma crônica moral e afetiva das sociedades contemporâneas, favorecendo o aprendizado de valores e modos de pensar o mundo e seus conflitos" (GUILHEM, 2007, p. 19). Por isso a escolha em repousar nossas análises em um filme, pois acreditamos que "os filmes constroem representações sociais e influenciam com- 
portamentos. Ao fazê-lo, podem estar a serviço de certos valores, interesses e concepções de mundo, mas também podem ser um instrumento poderoso de transformação social.” (GUILHEM, 2007, p. 14).

Louro (2010, p. 424) afirma que, ao estarmos em contato com o cinema, "distintas relações do sujeito com a imagem fílmica podem ocorrer: acolhida, ruptura, conformidade, resistência, crítica ou imprevisíveis combinações dessas e de outras respostas”. Por isso, seu poder dominante, a força e a abrangência de seus efeitos sociais nos fazem vê-lo como um espaço, sim, de construção de identidades culturais, capaz de interferir até mesmo nas redes sociais de poder, visto que "nesse processo de interação com a imagem há sempre um investimento de emoções".

Portanto, aos filmes é inerente os registros do passado e do contexto social e também a criação de reminiscências históricas próprias. Além disso, o cinema é uma fonte documental propensa a análises e investigações, já que, como todo registro, traz em si as marcas socioideológicas de uma determinada cultura, bem como suas concepções, representadas em tela a partir da leitura que se faz desta. Segundo Napolitano (2011), para analisar uma fonte audiovisual, como o cinema, deve-se considerar seus códigos internos, presentes em seu processo de construção de linguagem, e os mecanismos utilizados pela referida fonte quando deseja representar a realidade.

Para este estudo, elegemos o filme $O$ contador de histórias (Luiz Villaça, Brasil, 2009) sobre o qual repousaremos nossas análises. Na produção cinematográfica em questão, o protagonista Roberto Carlos tem sua infância [re]constituída a partir da sua vivência na Fundação Estadual para o Bem-Estar do Menor (FEBEM) e nas ruas, na década de 1970. Com base em alguns autores da literatura sobre cinema e a Sociologia da Infância, pretendemos focalizar a visibilidade cinematográfica da infância, retratada no filme, a partir de alguns frames ${ }^{2}$, com o intuito de refletir acerca da complexa teia de dependências recíprocas a qual pertencemos e as dificuldades que, como seres dependentes das ações sociais, temos ao nos desvencilhar da mesma.

2 Equivalente a quadro de imagem estática, fixa em um produto visual. 
A escolha do aporte teórico para este estudo, baseado na Sociologia da Infância, dá-se pelo fato de que este campo “...insere-se decisivamente na construção da reflexividade contemporânea sobre a realidade social" e de que "as crianças constituem uma porta de entrada fundamental para a compreensão dessa realidade” (SARMENTO, 2009, p. 19).

Para Silva (2011, p. 136), "todas as formas de conhecimento são vistas como o resultado dos aparatos - discursos, práticas, instituições, instrumentos, paradigmas - que fizeram com que fossem construídas como tais”. Assim, o cinema age como esse poderoso instrumento de representação de identidades, envolvendo as distinções de gênero, de classe, étnicas e sexuais, constituindo-se em uma pedagogia cultural abrangente.

Sob a compreensão de Caleffi (2011, p. 32), a educação é um processo amplo e que não está, necessariamente, submetido "[...] a um sistema de ensino institucionalizado", e sim "como o processo de socialização dos indivíduos em uma dada cultura”. Nesse caso, por espaço pedagógico/educativo deve-se entender as esferas e processos sociais que ultrapassam os limites da escola. Inclusive, como nos esclarece Louro (2010, p. 423), "as formas pelas quais essas instâncias interpelam os sujeitos diferem, contudo, daquelas em ação nas escolas e, consequentemente, também seus efeitos podem ser distintos".

Em O contador e histórias (Brasil, 2009), as representações presentes e reproduzidas permeiam um percurso histórico em que concepções de infância são postas em tela. Tais concepções são posicionadas sob diferentes formas advindas de diferentes enunciações de poder. Os discursos, as imagens, o jogo de cores e das câmeras, enfim, todo o conjunto de linguagem nele estabelecida compõem esse sistema de signos a ser desvelado, mas sem deixar de exercer um significativo papel como espaço pedagógico, isto é, como instância educativa em que o protagonista vivencia e exercita as diferentes formas de poder confrontadas por ele. 


\title{
Sessão única: O contador de histórias (Brasil, 2009) sob o olhar da sociologia da infância
}

\begin{abstract}
É preciso viver, por vezes é muito bom viver com a criança que fomos. [...] Muitas outras investigações seriam necessárias para esclarecer os dramas da infância, para mostrar sobretudo que esses dramas não se apagam, que podem renascer, que querem renascer. [...] A cólera dura, as cóleras primitivas despertam infâncias adormecidas. [...] Seria necessário um plano de pesquisa diferente do nosso para examinálas. (BACHELARD, 1996, p. 21)
\end{abstract}

No filme $O$ contador de histórias (Brasil, 2009), Luiz Villaça revive sua criança ao construir, na narrativa fílmica, a criança que Roberto Carlos Ramos foi, com seus dramas, seus conflitos, seu imaginário...

O interesse do diretor em transformar a história de vida do mineiro Roberto Carlos Ramos em filme surgiu ao ler um livro infantil para seu filho, de autoria do referido mineiro, onde, na contracapa da publicação, este descrevia a infância que teve. Assim, impressionado pelos dramas e transformações vividas, Villaça resolveu levar a história de Roberto às telas de cinema.

A película inicia com Roberto, nosso protagonista, já aos 13 anos, ferido e caminhando sobre os trilhos, revelando-nos, pela voz do narrador, que naquele dia ele decidiu morrer. Desejo estimulado por um momento trágico que Roberto vivera, em que precisou passar por um "ritual" instituído por um grupo de garotos. Quando desejou fazer parte de determinado grupo que detinha o poder na FEBEM - onde passou parte de sua infância - e até mesmo nas ruas, Roberto teve que se submeter ao ritual de sodomização imposto; ao tentar desistir, defender-se, foi violentado fisicamente.

Roberto, até os seis anos de idade, antes de ir para a FEBEM no início da década de 1970, vivia com a mãe, que ganhava a vida como lavadeira para sustentar seus dez filhos. Roberto era o mais novo dos filhos. Por causa da vida dura que levava, a mãe o interna na FEBEM de Belo Horizonte, com o intuito de que ele tivesse uma vida melhor e pudesse 
"virar doutor", conforme determinava campanha institucional veiculada na televisão:

Para que as crianças tenham um futuro elas precisam de cinco coisas: o $\mathrm{F}$ da fé, o E da educação, o B dos bons modos, o E da esperança, o M da moral. Sabe onde elas vão encontrar tudo isso? Na FEBEM. Aqui as crianças carentes terão a chance de se tornar homens do bem. Terão a chance de se tornar médicos, engenheiros, advogados. FEBEM, mais uma vitória do nosso governo. (O CONTADOR DE HISTÓRIAS, 2009)

Durante a propaganda, as imagens revelam crianças em situações em que qualquer criança pobre, desprovida de alguns de seus direitos, desejaria estar: em brincadeira de roda, em sala de aula equipada e com professora dedicada, alimentando-se de maneira adequada. As crianças aparecem sorrindo, satisfeitas, felizes e cheias de esperança.

Note-se que a intenção do comercial é apresentar uma visão de política para a institucionalização de crianças com garantia dos direitos da criança e do adolescente, com o intuito de que se acredite que os que se veem à margem da sociedade possam ser reintegrados de forma homogênea. Como se as disparidades sociais entre as classes pudessem ser dissipadas a partir da inserção de "crianças carentes" naquela instituição. No entanto, sabe-se que

As políticas para a infância têm implicado uma interação entre as instituições, estatais e privadas, públicas ou não, com troca de recursos, pessoas e serviços de umas para outras, nem sempre com transparência e rigor, e, constantemente na ótica do uso da máquina do Estado para interesses e patrimônios particulares. A esta concepção se contrapõe aquela que visa a garantia dos direitos da criança e adolescente, mas não hegemônica, em todos os setores do governo. (FALEIROS, 2011. p. 34-35)

E que, o cinema pode ser definido

Capturado pelas ilusões da técnica e desatento às implicações contidas na própria estrutura do olhar da câmera tal como se dá para nós na plateia. A técnica tem suas inclinações, seus efeitos ideológicos e, nesse sentido, é ela mesma que impele o cinema industrial a desenvolver seu ilusionismo e trazer o espectador para dentro do mundo ficcional. A força de encantamento desse 
cinema persiste na história porque o dado crucial em jogo não é tanto a imitação do real na tela - a reprodução integral das aparências -, mas a simulação de um certo tipo de sujeito do olhar pelas operações do aparato cinematográfico. (XAVIER, 2003, p. 48)

Nesse sentido, o filme em tela se traduz em um universo de opostos continuamente apresentados durante sua narrativa. Na propaganda traduzida para a tela, por exemplo, optou-se em simular toda a ironia entre a realidade e a ilusão. Edgar Morin destaca que é possível, no cinema, "o deslumbramento pelo universo arcaico dos duplos, das fantasias, nas telas, possuindo-nos, encantando-nos, vivendo em nós, vivendo para nós a nossa vida não vivida, alimentando nossa vida com sonhos, desejos, aspirações, normas..." (MORIN, 2014, p. 15), sem extinguir o sentimento da realidade. Assim, "o filme, em contrapartida, possui uma realidade externa ao espectador" e ao cinema, "um complexo de realidade e irrealidade” (MORIN, 2014, p. 183) - ação moderna da técnica maquinista da indústria cinematográfica.

Roberto Carlos, quando indagou à sua mãe de como era a FEBEM, teve por resposta de que era um lugar com "um monte de coisa boa”. A partir disso, ele acionou sua criação imaginativa e começou a desenhar, em seus pensamentos, um espaço com personagens circenses, cheio de cores, brinquedos, animação. Numa concepção moderna de infância,

O imaginário infantil é concebido como a expressão de um déficit - as crianças imaginam o mundo porque carecem de um mundo objetivo ou porque estão imperfeitamente formados os seus laços relacionais com a realidade. Essa ideia do déficit é inerente à negatividade na definição da criança, que constitui um pressuposto epistémico na construção social da infância pela modernidade. (SARMENTO, 2002, p. 2)

Entretanto, ao chegar lá, a realidade era bem diferente. As cores cinzentas e opacas tomaram conta daquele espaço, onde ele nem ao menos imaginava que ficaria por tanto tempo.

- Eu quero ir pra casa!

- Você vai acostumar, Roberto! Aqui não tem uma cama só pra

você? Não tem escola? Não tem comida? Aqui é bom, Roberto! 
- Você não quer mais eu, né mãe?

- Se você perguntar isso de novo te dou uma surra!

(O CONTADOR DE HISTÓRIAS, 2009)

E não demorou muito tempo para que aquele local se transformasse em um cenário bem distante das criações inventivas da criança. Um espaço que possibilitou a separação entre ele e sua mãe, onde nem ao menos respeitavam seu choro de saudade. O mesmo espaço que propiciou a Roberto transitar entre a docilidade e a revolta. Como aquele espaço não proporcionava qualquer esperança de transformação ou de que ele sairia de lá, adotou posturas transgressoras que contribuíram para que fosse considerado irrecuperável, como mencionava sempre a responsável da instituição: "Ele foge toda hora. Esse menino é um problema. A gente já tentou de tudo. Mas, parece que... não adianta [...] Já rouba, já fuma, já cheira cola... irrecuperável”. (O CONTADOR DE HISTÓRIAS, 2009).

No final das contas eu fugi umas cem vezes da FEBEM. Na verdade, eu nem sei por que eu fugia tanto. Lá eu tinha de tudo: companheirismo, comida de primeira, natação, orientação pedagógica, às vezes até quarto privativo. Mesmo com tudo isso, sempre que eu voltava pra FEBEM eu fugia de lá correndo. Dos sete aos catorze anos eu corri mais que jogador de futebol. (O CONTADOR DE HISTÓRIAS, 2009)

Nesse momento da narrativa, as imagens mostram o oposto do que é narrado em tom irônico. O Companheirismo, representado pelas surras que levava dos colegas maiores; a comida "de primeira", aproxima-se mais de uma babugem; a natação, as torturas sofridas nos tanques com água; a orientação pedagógica, os tapas corretivos dos funcionários da instituição; o quarto privativo, a cela solitária.

Há uma indissociabilidade entre memória e imaginação. Bachelard (1996) menciona que se reencontrar em sua própria história - reencontrar sua história de vida, relembrar sua infância, alegre ou triste - é cultivar a infância. Destaca que

A memória é um campo de ruínas psicológicas, um amontoado de recordações. Toda nossa infância está por ser reimaginada. Ao reimaginá-la, temos a possibilidade de reencontrá-la na própria vida dos nossos devaneios de criança solitária. [...] Há de- 
vaneios de infância que surgem como o brilho de um fogo. [...] Assim, as imagens da infância, [...] são para nós manifestações da infância permanente. (BACHELARD, 1996, p. 94-95)

Nesse sentido, vale ressaltar que, o imaginário infantil é peculiar às culturas infantis. Por culturas infantis, em consonância com o pensamento de Sarmento (2002, p. 3-4), entende-se "a capacidade das crianças em construírem de forma sistematizada modos de significação de mundo e de acção intencional, que são distintos dos modos adultos de significação e acção". Isto é, culturas infantis coadunam com a cultura de pares. A exemplo disso, podemos citar o momento na FEBEM, depois que Roberto foi transferido para a turma de alunos maiores (de 7 a 14 anos), onde teria "outras coisas pra fazer" e "outros meninos", Roberto percebeu que a principal coisa que se fazia lá era apanhar. E, para tentar se impor diante dos "outros meninos", Roberto ensaia com outro colega de idade próxima um repertório de palavrões, na tentativa de fazer-se "respeitar" pelos maiores. O palavrão, naquele momento, era uma metáfora de maturidade, coragem e passaporte para ser considerado como um dos meninos maiores, uma forma de se sentir aceito, incluído. O uso da linguagem, da criação vocabular e da semântica, seria a ordem da diferença, a estratégia.

A esse aspecto, Sarmento destaca que

A cultura de pares permite às crianças apropriar, reinventar e reproduzir o mundo que as rodeia, numa relação de convivência que permite exorcizar medos, construir fantasias e representar cenas do quotidiano, que assim funcionam como terapias para lidar com experiências negativas, ao mesmo tempo que se estabelecem fronteiras de inclusão e exclusão (de género, de subgrupos etários, de status, etc.) que estão fortemente implicados nos processos de identificação social. (SARMENTO, 2002, p. 11)

Neste processo, "as crianças acrescentam elementos novos e distintos aos seus comportamentos e culturas” (SARMENTO, 2004, p. 26). A exemplo disso, em outro momento do filme, Roberto, cansado de disputar as ruas com o grupo dos "outros garotos", tenta se aproximar do grupo rival a fim de ser aceito pelo chefe do grupo - "cabelinho de fogo". Para isso, ele menciona que já fumava, roubava e mostra a ele a "renda" que 
obteve no dia com seus furtos e roubos, pois seu desejo era ser como "cabelinho de fogo" que era como um rei das ruas. Sua postura vai de encontro aos valores até então por ele constituídos. Assim, o protagonista encontra formas de criar suas próprias maneiras de encontrar seu universo cultural.

Outro momento que Roberto age com essa postura "autônoma" e individual é quando, recebe a visita de sua mãe, depois de um largo espaço de tempo sem vê-la. Roberto age com indiferença diante de sua genitora, sem qualquer ato de afeto. A mãe, percebendo a indiferença, justifica sua ausência, mas se surpreende quando ouve de seu filho caçula o palavrão criado por ele e que já fazia parte de seu cotidiano. A câmera se aproxima do rosto de sua mãe, chamando-nos à atenção para a expressão de surpresa que a mesma demonstra para com a cena vivenciada. Essa mudança no comportamento de Roberto leva-nos à reflexão de que, segundo Sarmento (2004, p. 26), “o lugar da criança é, em suma, o lugar das culturas da infância. Mas esse lugar das culturas é continuamente reestruturado pelas condições estruturais que definem as gerações em cada momento histórico concreto". E que, “através de suas experiências, as crianças singularizam suas infâncias, porque, como seres ativos, eles buscam fazer o que desejam”. (MÜLLER, 2010, p. 15)

Toda a construção do personagem se dá entre os dias na FEBEM e os que ele vivia nas ruas, quando conseguia fugir. Depois, essa constituição foi tomando outros contornos quando ele conhece a pedagoga francesa que, por acreditar na pedagogia do afeto, não via a situação de Roberto como irrecuperável. O que nos incita a refletir que, de acordo com Delgado e Müller (2005, p. 352), "as crianças e os adultos devem ser vistos como uma multiplicidade de seres em formação, incompletos e dependentes".

\section{Algumas considerações}

Realizar estudos sobre a infância e sua história é refletir não apenas acerca dos mundos sociais e culturais de crianças e infâncias, mas ilumi- 
nar novos olhares para os mundos que constroem a nossa sociedade na sua multiplicidade. Por isso a relevância em ampliar o repertório de estudos que se ocupam com a infância e a história de suas crianças.

Na modernidade, o lugar da infância é um lugar em constante transformação, mas ela ainda não deixou de estar vinculada às desigualdades sociais, pois dificilmente teremos a extinção de crianças. Entretanto precisamos lutar para que a infância solidifique cada vez mais seu espaço na sociedade - não só no tempo e na história - a fim de garantir a participação infantil nas práticas sociais.

As mudanças sociais sofridas pela infância nos convidam a ampliar discussões acerca de estudos coerentes à sua história conduzindo-nos à reflexão contemporânea sobre a realidade social. Assim, seja no cinema ou em qualquer outra fonte documental, é importante conhecer as crianças que fazem parte de nosso grupo social para compreendermos as complexidades e contradições que se revelam em nossa sociedade. A aproximação de diferentes fontes e abordagens teóricas nos possibilita ver as crianças e a infância com novos olhares, desprovidos, talvez, de concepções embrutecidas que nos induzem a pensar a infância e a criança como seres inteiramente dependentes dos adultos e não como autores exclusivos de suas próprias culturas infantis.

Quem sabe assim, diferentes infâncias possam ser [re]constituídas numa perspectiva contínua e ascendente, em que crianças tenham diferentes papéis e estatutos sociais.

\section{Referências}

BACHELARD, Gaston. A poética do devaneio. São Paulo: Martins Fontes, 1996.

CALEFFI, Paula. Educação Autóctone nos séculos XVI ao XVIII ou Américo Vespúcio tinha razão? In: STEPHANOU, Maria; BASTOS, Maria Helena C. (Orgs.). Histórias e memórias da Educação no Brasil. V. 1: Séculos XVI - XVIII. 5. Ed. Petrópolis, RJ: Vozes, 2011. p. 32-44. 
CORSARO, William A. Sociologia da Infância. 2. Ed. Porto Alegre: Artmed, 2011.

DELGADO, Ana Cristina Coll; MÜLLER, Fernanda. Sociologia da Infância: pesquisa com crianças. Educação \& Sociedade, v. 26, n. 91, p. 351360, maio/ago. 2005. Disponível em: <http://www.cedes.unicamp.br>. Acesso em: 15 out. 2015.

DUARTE, Rosália. Cinema e Educação. Belo Horizonte: Autêntica, 2009. FALEIROS, Vicente de Paula Moreira. Infância e processo político no Brasil. In: RIZZINI, Irene; PILOTTI, Francisco (Orgs.). A arte de governar crianças: a história das políticas sociais, da legislação e da assistência à infância no Brasil. São Paulo: Cortez, 2011. p. 33-96.

GUILHEM, Dirce. Pelas lentes do cinema: bioética e ética em pesquisa. Brasília: Ed. UnB, 2007.

LOURO, Garcia Lopes. O cinema como pedagogia. In: LOPES, Eliane M. T.; FILHO, Luciano M. F.; VEIGA, Cyntia G. (Orgs.). 500 anos de Educação no Brasil. 4. ed. Belo Horizonte: Autêntica, 2010.

MORIN, Edgar. O cinema ou o homem imaginário: ensaio de Antropologia Sociológica. São Paulo: É Realizações Editora, 2014.

MÜLLER, Fernanda. Infância em perspectiva: políticas, pesquisas e instituições. São Paulo: Cortez, 2010.

NAPOLITANO, Marcos. Fontes audiovisuais: a história depois do papel. In: PINSKY, Carla B. (Org.). Fontes Históricas. São Paulo: Contexto, 2011.

O CONTADOR DE HISTÓRIAS. Direção de Luiz Villaça. Produção: Francisco Ramalho Jr. e Denise Fraga. Roteiro: Mauricio Arruda, José Roberto Torero, Mariana Veríssimo e Luiz Villaça. Baseado na história de Roberto Carlos Ramos. 2009. DVD (100 min.).

SARMENTO, Manuel Jacinto. As culturas da infância nas encruzilhadas da segunda modernidade. In: ; CERISARA, A. B. Crianças e Miúdos: perspectivas sociopedagógicas da infância e educação. Porto, Portugal: Asa Editores, 2004. p. 9-34.

. Sociologia da Infância: correntes e confluências. In:

GOUVEA, Maria Cristina Soares de (Org.). Estudos da Infância: Educação e Práticas Sociais. 2. Ed. Petrópolis, RJ: Vozes, 2009. p. 17-39. (Coleção ciências Sociais da Educação).

. Imaginário e culturas da infância. Instituto de Estudos da Criança. Universidade do Minho/Portugal. Projeto As marcas dos Tempos: a Interculturalidade nas Culturas da infância. Projeto POCTI/CED/49186/2002. Disponível em: <http://titosena.faed.udesc.br/Arquivos/Artigos_infancia/Cultura\%2on a\%20Infancia.pdf $>$. Acesso em: 17 nov. 2015. 
SILVA, Tomaz Tadeu da. Documentos de Identidade: uma introdução às teorias do currículo. 3. ed. Belo Horizonte: Autêntica, 2011.

XAVIER, Ismail. O olhar e a cena: melodrama, Hollywood, cinema novo, Nelson Rodrigues. São Paulo: Cosac \& Naify, 2003.

Recebido em 10 de maio de 2016. Aprovado em 10 de agosto de 2016. 